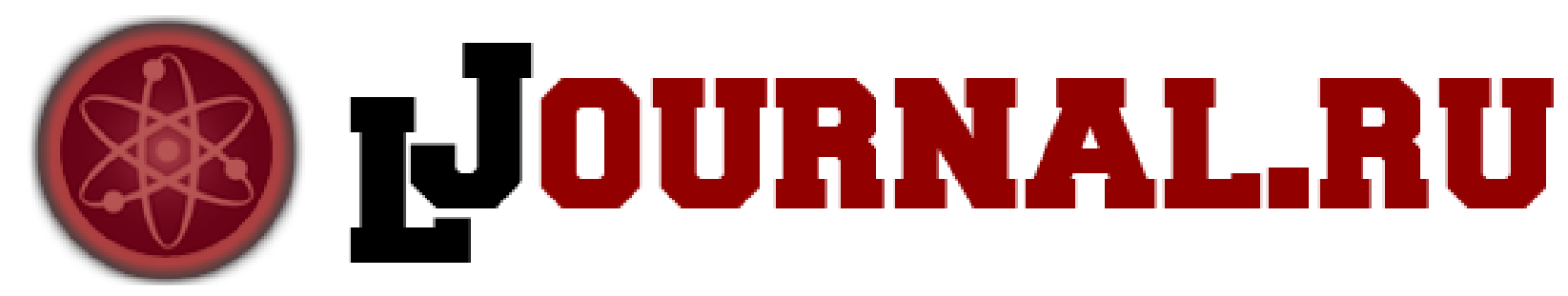

Дерюгина Е.Г. Санкт-Петербургская академия постдипломного педагогического образования Санкт-Петербург, Россия

doi: 10.18411/1j2016-2-05

\title{
Особенности социально-педагогических условий частной школы
}

Современное образовательное пространство России представлено широким спектром учреждений, где, наряду с государственными, значительную нишу занимают и учреждения частные. Их возникновение в постсоветский период, как и в дореволюционное время, было продиктовано потребностью общества в создании иных условий для образования, альтернативных существующим. Актуальным вопросом современности является вопрос о том, каковы социально-педагогические условия частной школы, поскольку от них зависит качественный уровень всей системы частного образования.

Обращаясь к истории возникновения в России частных образовательных учреждений, следует отметить, что основной их расцвет приходится на дореволюционный период второй половины XIX - начала XX в. После искоренения системы частного образования в советское время, новый всплеск создания частных школ происходит в период перестройки конца XX века. Между этими периодами можно находить параллели, дающие возможность выявлять общие закономерности развития частных школ, формирования их социально-педагогических условий, а также видеть существенные отличия школьной среды различных времен, обращаться к бесценному опыту прошлого. О важности «образования школьной средой», основываясь на истории дореволюционных петербургских учебных заведений, говорит А. Н. Шевелев 
[11. С. 114]. Создание особой среды частных школ в каждом отдельном случае стало возможным благодаря воле, жизненной энергии и сформированной, глубоко продуманной педагогической позиции талантливого руководителя образовательного учреждения. Проанализировав причины возникновения частных учреждений и цели, которые ставили перед собой их создатели, мы можем прийти к осознанию тенденций, характерных для частного образования.

В дореволюционные годы в России создание многих частных школ было определено подъемом общественно-политического движения, когда общество, видя несостоятельность существующих казенных систем, стремилось их изменить. Значимость влияния общества на становление школы подчеркивал А. Я. Острогорский - директор Тенишевского училища, одного из самых знаменитых частных учреждений дореволюционной России: «Всякая школа есть дело общественное, она должна отвечать нуждам и запросам общества, а потому построение ее не может идти помимо общества, без его непосредственного и ближайшего участия. Игнорирование этого элементарного положения не может не отразиться самым неблагоприятным образом на судьбах самой школы». [6. С. 162]. Хочется отметить, что в конце XIX - начале XX века создание частных школ носило миссионерский характер, и люди, посвятившие этому делу свою жизнь, все силы и собственные сбережения вкладывали в поддержание и развитие школьной среды.

Анализируя обстоятельства возникновения частных школ в конце 90-х годов XX века, отметим следующую специфику. Как отмечает А. Л. Вильсон , их создавали «во-первых, преподаватели, которых не устраивала советская школа, им казалось, что эта вольность - возможность работать индивидуально, создавать свои образовательные структуры - даст возможность по-другому подойти к созданию школы, с других позиций, которые не были реализованы в советской школе. Во-вторых, это бизнесмены достаточно успешные, у которых есть дети, и которых по ряду причин не устраивала советская школа. Они создавали школы «под» своих детей. И третья группа - чиновники, 
администраторы из сферы образования, в прошлом руководители, которые, пользуясь административным ресурсом, связями, могли получить помещение и открывали платные школы» [12. С. 78]. Если обратиться к статистике, то на данный момент около 40\% частных школ Санкт-Петербурга возглавляются учредителями, взявшими на себя обязанности директора образовательного учреждения, если же рассматривать ситуацию в среднем по России, то это уже относится к 80\% частных школ. Для директора частной школы не является преградой отсутствие у него педагогического образования. При этом личное мнение директора о том, как должно быть устроено образовательное пространство его школы, во многом, является решающим и определяет жизнедеятельность всего учреждения. При этом требования, выдвигаемые к компетентности директора любой школы, а особенно частной, колоссальны. Как утверждает А. Л. Вильсон, «...директор в частной школе отвечает за все. Он должен быть и хорошим дипломатом, хорошим коммерсантом, хозяйственником и хорошим педагогом» [12. С. 82]. Всю жизнедеятельность школы определяет профессиональная позиция директора как педагога.

При рассмотрении особенностей, свойственных среде негосударственного общеобразовательного учреждения, следует отметить специфику контингента учащихся, который является более дифференцированным, чем в школе государственной. M. Вольфсон и $\mathrm{M}$. Эпштейн приводят данные социологического опроса , определяющие основные группы учащихся, наиболее нуждающиеся в альтернативном образовании. Это дети, которым хотелось бы больше свободы и уважения - 40\% опрошенных; дети со специальными интересами (например, музыкальными, спортивными, научными и т.д.) - 38\%; ученики, имеющие проблемы с учебой - 29\%; дети с ограниченными физическими возможностями - 29\%; одаренные дети - 25\% [2]. А. Л. Вильсон отмечает, что «...негосударственный сектор дает возможность получить хорошее образование трудным детям и детям со специальными нуждами, которые в обычных школах и вузах, как правило, в массе своей оказываются „на 
обочине“ и устойчиво отстают» [1. С. 3].

Большинство частных школ ставит своей задачей работу с детьми, «имеющими реальные или потенциальные проблемы в обучении, социальной адаптации или реализации своих способностей» [10], предусматривают «особый подход к детям, которые могли бы развиваться и воспитываться по-новому, избегнув педагогической штамповки последних десятилетий, калечащей подчас судьбы нестандартных, особенных детей, не желающих или не способных вписаться в ограниченные куцые правила нормативов, «оболванивающих» личность ребенка и лишающих ее природной неповторимости» [3].

Одновременно с этим следует учитывать, что основным контингентом частных школ являются дети, образование которых финансируется родителями. Специфика семейных отношений определяет различные категории учащихся из состоятельных семей со значительными различиями в воспитании и личном отношении к процессу обучения, например, такие как:

- «золотые» дети - имеющие хорошую образовательную базу, привыкшие серьезно относиться к учебе. Родители всячески поддерживают детей, внимательно относятся к процессу образования, осуществляют достаточно серьезный контроль образовательного процесса. Зачастую это семьи, относящие себя к «элите». Существуют частные школы, нацеленные в основном на данный контингент учащихся. Например, частная школа «Дипломат» Санкт-Петербурга одной из главных задач считает «формирование поколения успешных людей, духовной и социальный элиты нашего общества», называя себя «школой будущих аристократов» [9];

- «заброшенные» дети - имеющие сложности с учебой в результате отсутствия должного внимания родителей. В большинстве подобных случаев родители, сильно занятые коммерцией, стараются переложить свои функции по участию в процессе образования детей всецело на школу, «откупаясь» от необходимости тратить время и собственные силы для взаимодействия с ребенком; 
- «трутни» — дети, убежденные в том, что «все покупается, в том числе и аттестат», сознательно не желающие прикладывать собственных усилий к обучению. Подобная категория учащихся с момента введения ЕГЭ стала не так многочисленна, но продолжает существовать.

Зачастую в частных школах представлены различные категории учащихся, что осложняет работу педагога с детским коллективом. В связи со значительной дифференциацией контингента учащихся педагогу частной школы необходимо иметь определенные черты характера и способности, чтобы работать с настолько различающимися категориями детей, быть готовым к иному стилю взаимоотношений между преподавателем и учащимися, отсутствию «рычагов давления» и стимулов управления детским коллективом, свойственных государственным учреждениям. Вот как говорит об особенностях, характерных для педагогов частных школ, А. Л. Вильсон: «...даже сегодня мы часто сталкиваемся с тем, что учителя, которые пришли к нам из средней государственной школы, не понимают сразу тонкостей работы в частной школе. В государственной школе учитель независим, самодостаточен, он - это несколько утрированно прозвучит сейчас - выполняет государственную миссию, ему дана задача - учить детей. И как он учит - это не ваше дело, „я учу, как меня учили и как я считаю правильным"» [12. С. 79].

От учителя, работающего в частной школе, требуется большая мобильность, гибкость в отношении к образовательному процессу, демократичность во взаимоотношениях с коллегами и детьми, наличие гуманистических взглядов на процесс образования. По словам А. Л. Вильсона «...учитель частной школы должен быть мобильным, должен постоянно отрабатывать новые формы работы в дифференцированном классе по уровню подготовки детей. В этом принципиальное отличие частной школы от государственной» [12. С. 78]. Кроме того, как указывает А. Л. Вильсон, опираясь на собственный опыт работы в частной школе, постоянно изменяется (ориентировочно на 10\% в год) контингент учащихся внутри классного 
коллектива, что связано с «текучестью» родителей (поскольку ребенка отдают в частную школу в соответствии с материальными возможностями семьи, которые при современной экономической ситуации могут в любой момент значительно измениться). При этом Вильсон добавляет, что «... чаще всего эти 10\% и набираются, и за десять лет один класс может обновиться вообще на 100\%. Такое бывает, это нормальная цифра, характерная для частной школы, но для государственной — это нонсенс» [12. С. 79].

В частной школе существует специфика формирования педагогического коллектива. В государственной школе при приеме на работу учителя главным запросом является знание преподаваемого предмета на должном уровне, желательным является наличие значительного педагогического опыта. Педагог, собирающийся устроиться на работу в государственную школу, идет, прежде всего, «на предмет», видя перед собой главной задачей преподавание. В государственных школах даже существует определенный конфликт между областью обучения и воспитания, т.к. у многих учителей-предметников существует установка, что главное для ребенка - изучение его предмета, область воспитания часто рассматривается как второстепенная.

В частной системе идут «на школу» - в соответствии с личными убеждениями и при разделении существующей идеологии именно этого учреждения, соглашаясь с концепцией и идеологией школы. Учитель частной школы зачастую считает себя именно педагогом, выполняющим особую воспитательную миссию. В альтернативной школе огромное значение уделяется наличию профессиональной позиции, во многом совпадающей с концептуальной позицией школы, личным разноплановым умениям учителя, многогранности его интересов, собственному видению учителем образовательного пространства, близкому к видению педагогического коллектива. Например, в анкете претендента на вакансию при собеседовании в частной школе «Взмах» есть такие пункты, как «ваши три достижения в жизни», «что Вам в себе нравится», «ваши увлечения». Общим для большинства частных 
школ является то, что учителя — это «...достойные и интересные люди, которые не боятся нового и всегда готовы поучиться, способны признавать свои заблуждения и постоянно совершенствоваться в профессиональном и человеческом смысле, дарят себя детям, не жалея сил и свободного времени и получая от этого радость» [5]. Анализируя главную цель деятельности частной школы «Взмах» Санкт-Петербурга, обозначенную как «воспитание свободного, творчески мыслящего, широко образованного человека - гражданина мира, уверенного в себе, открытого людям, умеющего быть счастливым в жизни и успешным в деятельности» [8. С. 1], можно отнести как минимум те же требования и к любому педагогу школы, осуществляющему такое воспитание. Эти требования во-многом определяют профессиональную позицию, которая должна быть сформирована у педагога, стремящегося работать в данном образовательном учреждении. Учитель здесь должен быть не просто хорошим «предметником», а, прежде всего, иметь сформированную профессиональную и личную жизненную позицию. Наиболее часто в основе создания частной школы лежит коллектив единомышленников, стремящийся воплотить в жизнь свое видение образовательного процесса.

В частной школе педагог ясно понимает возможность конкуренции, «держится» за свое место, прикладывает усилия для самосовершенствования, которые не продиктованы просто стремлением номинально пройти аттестацию. Если педагог не устраивает педагогический коллектив или лично директора ему находится замена. Для руководства государственного образовательного учреждения существует проблема «сложности отсева»: увольнение из государственной школы практически может осуществляться только в одностороннем порядке — при самостоятельном решении учителя покинуть данное учебное заведение. Даже в случае отсутствия стремления работать, многие держаться за место из-за существующих удобств. «Вот приходит молодой специалист, он может ошибаться, но если талант есть, всегда видно: это — уже учитель. А бывает, человек идет в учителя от безысходности. В школах 
часто работают почему? Потому что близко к дому, график работы удобный...» [4. C. 84].

В частных школах существует разный подход к наличию педагогического образования сотрудников. В некоторых школах высшее педагогическое образование является практически обязательным для приема на работу, также внимание уделяется аттестационной категории, преимущественно высшей, но существуют и школы, в которых не придают большого значения наличию специального образования, большее внимание уделяется харизме, наличию активной жизненной позиции, потому к преподаванию часто подключаются люди непедагогических специальностей, что может отражаться на уровне их профессионализма.

В частных школах существуют также значительные отличия кадровой политики и административного взаимодействия с педагогическим коллективом. Для частной структуры характерны негативные проявления, такие как:

- существование жесткой управленческой вертикали. Зачастую директор (учредитель) является лицом, авторитарно решающим ряд значимых для педагогического коллектива вопросов, в том числе относящихся к функциям и занятости педагогов. В связи с этим надо отметить проявляющееся административное давление, касающееся вопросов содержания, стиля преподавания, временных затрат учителя;

- «ревностное» отношение к временным затратам педагога. В связи с тем, что рабочее время в частной школе напрямую связано с финансовыми вопросами, в некоторых школах педагог сталкивается с убеждением директора, что любая трата педагогического времени должна происходить исключительно в стенах данного образовательного учреждения. Стремление педагогов участвовать в «сторонних» конференциях, семинарах и прочих мероприятиям, способствующим обмену опытом педагогов вне конкретной школы, достаточно часто вызывает у директора скептическую или явно негативную оценку, даже если организацией на своей базе мероприятий районного, городского уровня 
учреждение не занимается. Подобное отношение приводит к своего рода «закупориванию» образовательного пространства школы, серьезному ограничению возможностей для совершенствования профессиональных умений педагога, повышения его компетентности. Исключение иногда составляет отношение администрации к образованию педагога по профилю, но это определяется заинтересованностью директора в официальном повышении профессионального статуса своего сотрудника;

- возможность потери педагогом своего рабочего места в случае несовпадения личной профессиональной позиции педагога с идеологией школы, несоответствия ожиданиям, на него возложенным, личных или профессиональных разногласий с учредителем, родительским или детским коллективом. «Если три четверти класса требует сменить учителя, то этого учителя заменят. В госшколе трудно такое представить, должно произойти что-то очень серьезное. А в частных школах это сплошь и рядом», - А. Л. Вильсон [12. С. 79];

- финансовая зависимость педагога от субъективной оценки его педагогического труда учредителем: установление размера заработной платы, премии, штрафы, и прочие выплаты в основном зависят от личных договоренностей и взаимоотношений с директором школы (учредителем).

При этом для любого педагога необходимо осознание значимости своей педагогической позиции, ценности собственной индивидуальности в образовательном процессе. Недаром еще в дореволюционное время А. Я. Острогорский писал: «Дайте педагогу самостоятельность, независимость, право личной инициативы, возможность быть полноправным членом общества, средства получить надлежащее необходимое ему образование, и тогда у него явится и педагогический такт, и серьезное отношение к делу, и личный авторитет в глазах учеников» [6. С. 170]. В частной школе порой возникают противоречия, вызванные встающей перед педагогом необходимостью «вписаться» в социально-педагогические условия учреждения, не изменив 
собственному видению образовательного процесса. Важно, чтобы учитель, согласовывая свою профессиональную позицию с концептуальным видением образовательного процесса педагогического коллектива школы, сохранял свою индивидуальность.

Одной из особенностей частной школы является тот аспект, что финансирование образования обеспечивается семьями учащихся, что зачастую определяет неоднозначный характер взаимоотношений между педагогами и родителями. Родители, являющиеся главными спонсорами учебного заведения, часто обозначают стремление к контролю осуществляемого образовательного процесса. В частных школах существует «...тонкая грань между контролем и диктовкой, что как делать со стороны родителей. И если педагогическому коллективу встать на позицию „чего изволите?“, то все, школа умерла», - А. Л. Вильсон [12. С. 80]. Но при этом надо учитывать, что частные школы возникали в ответ на запрос общества об иной среде обучения, и родители в данном контексте во многом олицетворяют это общество, поэтому не прислушиваться к запросам родителей в частной школе невозможно. Для частной школы важен приход педагогического коллектива и родительской общественности к продуктивному сотрудничеству. Это непростая задача, с которой каждая школа справляется по-своему. Значимость установления позитивных взаимоотношений между семьей и школой была признана еще в дореволюционное время, когда в казенных гимназиях общение с родителями было сведено до минимума, и именно директора частных образовательных учреждений выступали за поиск путей взаимодействия. В соответствии с материалами, сохранившимися $\mathrm{c}$ заседания комиссии П. П. Извольского в Санкт-Петербурге от 30 ноября и 7 декабря 1904 г., можно видеть позицию директоров частных учебных заведений, высказываемую при рассмотрении мер, «способствующих преодолению розни семьи и школы». Т. И. Пашкова, анализируя поднимаемые в ходе обсуждений предложения по взаимодействию школы с родителями, выделила такие, как: устройство частых бесед родителей с преподавателями и классными 
наставниками по поводу успехов и поведения, рассылка письменных оповещений родителей о ходе занятий; устройство постоянных педагогических (родительско-педагогических) кружков (предложения, высказанные директором частной гимназии А. Я. Гуревичем); создание попечительных советов (комитетов) из родителей и педагогов; открытие дверей школы для всех заинтересованных лиц, а не только для родителей; свободное обращение родителей к директору и преподавателям (А. Я. Острогорский); устройство совместных собраний родителей с преподавателями; создание самостоятельных родительских кружков (М. Н. Стоюнина); устройство родительских собраний общих и классных. Даже были смелые предложения, основанные на личном опыте, по поводу «допущения родителей на уроки» и участия родителей в педсоветах (А. Я. Острогорский) [7. С. 153-154]. Как мы видим, многие предложения директоров дореволюционных частных школ актуальные и в наше время.

При рассмотрении особенностей социально-педагогических условий частных школ мы видим, что существует определенная специфика контингента учащихся, принципов формирования педагогического коллектива, профессиональной позиции педагогов, кадровой политики, административного взаимодействия c педагогическим коллективом, взаимоотношений родителями. Учет данных особенностей и внимательное изучение опыта дореволюционных частных образовательных учреждений позволяет осознавать многие положительные стороны и проблемные точки частного образования и выстраивать конструктивный диалог с современной частной школой, являющейся на современном этапе неотъемлемой частью российской системы образования. 


\section{Литература:}

1. Вильсон А. Л. Совершенствование общественного управления процессом развития негосударственного образования / А. Л. Вильсон // Образование в современной школе. 2008. № 11. С. 3-8.

2. Вольфсон М., Эпштейн М. Кому и зачем нужно альтернативное образование? // На путях к новой школе, 2005. № 1: [сайт]. URL: http://www.altruism.ru/sengine.cgi/5/7/8/19/10 \{дата обращения: 22.02.16\}

3. История школы. Сайт школы «Дельта»: [сайт]. URL: http://www.shkoladelta.ru/istoriya.html \{дата обращения: 22.02.16\}

4. Лихачев Д. Б. Трудная школа. // Нескучный сад. 2007. № 8.

5. Наши учителя. Сайт школы «Дельта»: [сайт]. URL: http://shkoladelta.ru/teachers.html \{дата обращения: 22.02.16\}

6. Острогорский А. Я. Как же устроить нашу среднюю школу? // Образование: журнал литературный, научно-популярный и педагогический. 1903. № 9.

7. Пашкова Т. И. «Рознь семьи и школы» и поиски путей ее преодоления в начале XX века / История - современности. Universum: Вестник Герценовского университета. 2013, № 1.

8. Устав частной школы «Взмах»: [сайт]. URL: http://vzmakh.com/ftpgetfile.php?id=17 \{дата обращения: 22.02.16

9. Частная школа «Дипломат»: [сайт]. URL: http://diplomatschool.ru

10. Частная школа «Ювента»: [сайт]. URL: http://www.nwedu.ru \{дата обращения: 27.12 .15$\}$

11. Шевелев А. Н. Образовательная урбанистика: методологические аспекты изучения школьной среды петербургских дореволюционных учебных заведений: Монография / А.Н. Шевелев. СПб.: СПбАППО, 2008. - 127 с.

12. «Штучное» образование // Персона гранта. Директор школы. 2009. № 10. 